\title{
Instituições de ensino superior públicas em Portugal sua administração sob as premissas da New Public Management e da crise econômica global
}

Instituto Politécnico de Coimbra,

MIGUEL LIRA Instituto Politécnico de Coimbra,

Coimbra, Portugal

MIGUEL GONÇALVES Instituto Politécnico de Coimbra, Coimbra, Portugal

MARIA DA CONCEIÇÃO DA COSTA MARQUES Instituto Politécnico de Coimbra, Coimbra, Portugal

RESUMO

$\mathrm{O}$ artigo apresenta uma revisão da literatura sobre o presente cenário da administração das instituições de ensino superior públicas, com destaque para o caso de Portugal, designadamente quanto ao impacto que a introdução do paradigma da New Public Management e os efeitos que a crise económica e financeira mundial produziram nas instituições de ensino superior públicas. $\mathrm{O}$ estudo tem por base pressupostos teóricos interpretativos e adota como metodologia a abordagem qualitativa e como método de investigação o bibliográfico.

PALAVRAS-CHAVE

administração; ensino superior; instituições de ensino superior públicas; New Public

Management. 


\section{PUBLIC INSTITUTIONS OF TERTIARY EDUCATION IN PORTUGAL: THEIR ADMINISTRATION UNDER NEW PUBLIC MANAGEMENT AND THE GLOBAL ECONOMIC CRISIS}

\section{ABSTRACT}

This paper presents a literature review about the present situation of the administration of public institutions of higher education, with special reference to the portuguese case, particularly on the impact of the introduction of the paradigm of Nerw Public Management and the effects of the global financial and economic crisis on institutions of public higher education. The study is based on interpretative theoretical assumptions, adopting a qualitative methodology and a bibliographic research method.

\section{KEYWORDS}

administration; tertiary education; public tertiary education institutions; Nerw Public Management.

\section{INSTITUCIONES DE EDUCACIÓN SUPERIOR PÚBLICAS EN PORTUGAL: SU ADMINISTRACIÓN BAJO LAS PREMISAS DE LA NEW PUBLIC MANAGEMENT Y LA CRISIS ECONÓMICA GLOBAL}

\section{RESUMEN}

En este trabajo se presenta una revisión de la literatura sobre la situación actual de la administración de las instituciones públicas de educación superior, con énfasis en el caso de Portugal, especialmente en relación con el impacto que la introducción del paradigma de la Nerw Public Management y los efectos de la crisis financiera y económica mundial han producido en las instituciones de educación superior pública. El estudio se basa en presupuestos teóricos interpretativos, la metodología sigue un enfoque cualitativo, y el método de investigación es el bibliográfico.

\section{PALABRAS CLAVE}

administración; educación superior; instituciones públicas de educación superior; New Public Management. 


\section{INTRODUÇÃO}

Dada sua importância para a sociedade, as instituições de ensino superior (IES) são objeto de avultados investimentos, tanto públicos como privados, o que leva a que as expetativas que lhe são impostas sejam extremamente elevadas. De forma a restituir à sociedade o investimento nelas realizado, as IES não podem descurar as necessidades vitais da sociedade contemporânea, ou seja, essas instituições não podem deixar de lado a inovação e as estruturas internas que permitam satisfazer suas missões (cf. Johnstone; Teferra, 2004; Machado; Taylor, 2010).

Essa tarefa, todavia, não se avizinha nada fácil, atendendo que os desafios que se lhes colocam atualmente são complexos, destacando-se de entre estes: (a) a crise económica e financeira que assola o globo desde 2008; (b) a invasão das forças de mercado no ensino superior decorrentes da influência da New Public Management (NPM); (c) e o aumento das pressões competitivas da globalização.

É consensual que as IES atravessam presentemente um período de considerável turbulência e de mudança (Zaharia, 2002), fruto das mais recentes alterações no ambiente em que essas organizações operam (DeShields; Kara; Kaynak, 2005). Por esse motivo, não será difícil inferir que os sistemas educativos têm experimentado grandes processos reformatórios, assistindo-se a algumas tendências universais, como a ênfase nas forças do mercado, a melhoria da eficácia escolar e a competência do professor (Humes, 2000).

Daqui decorre que o interesse pela administração das IES - e a pertinência de seu estudo - aumenta se considerarmos que a administração e a liderança no ensino superior enfrentam atualmente seu maior desafio, fruto do atual cenário de complexidade institucional no nível dessas instituições. É essa realidade que esta comunicação explora.

O objetivo deste trabalho centra-se na análise das diversas mutações ocorridas nos últimos anos no seio das IES públicas, com destaque para o caso português. Assim sendo, não deixará de ser abordado e dissecado o impacto que a introdução do paradigma da NPM e os efeitos da crise económica e financeira mundial produziram nessas instituições, nomeadamente no nível de sua administração e de seu financiamento. Em suma, procuraremos obter respostas a questões, entre outras que se apresentam, tais como: Quais os indícios da presença das doutrinas da NPM na administração das IES públicas portuguesas? A atual filosofia por detrás da administração dessas instituições é managerialista, tradicional ou híbrida? A realidade portuguesa nessa matéria difere da de outros países?

Tendo em conta esse objetivo, o texto está estruturado em cinco secções, para além da secção inicial introdutória. A segunda secção aborda a problemática da administração das IES públicas sob o signo da NPM e da crise mundial. A terceira enuncia as alterações ocorridas no financiamento do ensino superior público fruto da influência da crise mundial e da NPM. Trata a quarta seção dos modelos híbridos de governação das IES, e a quinta analisa o caso concreto do ensino superior público português. $O$ texto encerra com a apresentação das conclusões, limitações e recomendações do trabalho. 


\section{A ADMINISTRAÇÃO DAS IES PÚBLICAS SOB O SIGNO DA NPM E DA CRISE MUNDIAL}

Em 2008, assistimos ao despoletar do maior desastre e colapso económico e financeiro desde a Grande Depressão que se iniciou em 1929 (cf. Lains, 2012; McCann, 2013). Embora não seja possível datar em termos precisos o início da presente crise financeira global, o marco mais utilizado para identificar seu princípio é a chamada crise do subprime ocorrida nos Estados Unidos (Lains, 2012), visto esta ter servido de rastilho para o colapso - ou ao quase colapso - de muitos bancos privados (Lodge; Hood, 2012).

Em termos muito sintéticos, as inadimplências das hipotecas norte-americanas começaram a subir no início de 2007, resultando em falências entre os credores hipotecários de subprime. No verão desse ano, os principais bancos centrais mundiais empreenderam injeções coordenadas de liquidez no sistema financeiro mundial. A partir de início de 2008, o sistema financeiro norte-americano começou a mostrar claros sinais de rotura (cf. os casos Bear Stearns e Indymac Bank), mas foi só no início de setembro que o termo crise financeira começou a ser utilizado após os problemas no sistema financeiro norte-americano terem aumentado de forma exponencial (cf. os casos Fannie Mae, Freddie Mac, Merrill Lynch, Lehman Brothers, AIG, Northern Rock).

Dadas as interdependências estruturais que operavam (e operam) em nível global, não será, de todo, surpreendente que a partir do final do verão de 2008 a crise financeira se tenha espalhado com uma notável rapidez por todo o sistema financeiro global, prejudicando muitas das maiores instituições financeiras mundiais, tendo sido acompanhada, posteriormente, por uma recessão, à escala mundial, na chamada economia real. Por outras palavras, a juntar à crise estritamente financeira, tivemos, igualmente, uma crise económica que se disseminou por qualquer país ou entidade económica aberto à globalização, incluindo os mais bem-sucedidos exemplos de inovação e/ou crescimento das exportações, como o Japão, a Alemanha ou a Coreia do Sul (cf. Boyer, 2012), muito embora os níveis de intensidade dessa crise tenham divergido por entre as diferentes regiões e países do mundo (cf. Zagelmeyer; Gollan, 2012).

Lodge e Hood (2012) notam que, volvidos três anos desde seu início, essa crise estendeu-se e sofreu nova mutação: desbocou em uma crise de dívida soberana, em parte por causa da transferência da dívida privada para o setor público; embora em alguns países específicos a crise da dívida soberana tenha derivado, igualmente, do sobre-endividamento estatal, como é o caso português.

Em termos de consequências, essa crise global induziu uma renovada avaliação do papel do Estado e do setor público, para além das profundas implicações para as finanças públicas daí decorrentes (cf. McCann, 2013). Em suma, "nesta era de austeridade fiscal, as organizações públicas estão sob uma pressão cada vez maior para administrar os seus serviços dentro de orçamentos cada vez mais apertados" (Andrews; Boyne; Walker, 2012, p. 39). Essa observação é deveras importante para nosso trabalho, visto que esse cenário de crise generalizada levou a cortes colossais no valor da despesa inscrito nos orçamentos das instituições públicas, incluindo as IES. 
Porém, antes de os efeitos da presente crise económica e financeira fazerem-se sentir nas IES públicas, outro fenómeno já tinha levado ao aparecimento de novas formas de hierarquia, identidade e racionalidade nessas organizações (Willner; Grönblom, 2009), designadamente a introdução das doutrinas da NPM nas IES públicas.

Mas o que é a NPM? De um ponto de vista teórico, os pontos nevrálgicos da complexa amálgama de teorias e ideologias que compõem a NPM foram sintetizados em 1991 por Christopher Hood. O conceito central de seu argumento era simples: para assegurar um desempenho eficiente, o setor público devia pedir emprestado as ferramentas, os valores e os termos utilizados no setor privado. Subjacente a essa nova filosofia está, portanto, a crença de que as práticas, os métodos e os princípios utilizados na gestão do setor privado são superiores aos usados na administração do setor público (cf. Hood, 1991). Daí que nas reformas administrativas apoiadas nas doutrinas subjacentes à NPM foi observada a utilização de instrumentos há muito presentes no setor privado, tais como gestão por resultados, introdução de medidas de desempenho, contratos com base no desempenho, competição, incentivos de mercado, orientação para o consumidor ou cliente, privatização de entidades públicas etc. (cf. Hood, 1991; Kaboolian, 1998; Kettl, 1997; Lane, 2000; Pollitt; Bouckaert, 2004, por exemplo).

Como não podia deixar de ser, a influência de tal paradigma chegou ao ensino superior público e às suas organizações. Dessa forma, e como resultado tanto das pressões transnacionais como das exigências domésticas, a administração das IES públicas foi remodelada, transformada, modernizada e, em muitos casos, mercantilizada (Dobbins; Knill; Vögtle, 2011, p. 666), já que nesse contexto as formas tradicionais de administração académica baseadas na colegialidade são vistas como obsoletas, ineficazes, ineficientes e desresponsabilizantes, sendo apresentadas como obstáculos à boa administração das IES (cf. Lima, 2009; Lorenz, 2007).

A introdução dessa nova filosofia levou à formação de mercados ou quase mercados em educação superior, resultando na competição por alunos e por financiamento para a investigação; no financiamento com base em resultados, sobressaindo a figura do contrato de desempenho; e na autonomia institucional para gerir com eficácia (Dias, 2008; Ferlie; Musselin; Andresani, 2008; Santiago, 1998; Tang; Tang, 2012).

Além disso, assistiu-se a uma alteração do papel dos docentes quanto ao desempenho das funções dirigentes. Muitas das vezes, estes são removidos do centro da tomada de decisão, em detrimento de uma maior profissionalização da administração (cf. Ferlie et al., 1996; Maassen, 2008; Rhoades; Sporn, 2002; Scott, 2011; Teichler, 2003, por meio do recurso a profissionais especializados nessa área (Rocha, 2000). Dessa forma, um dos resultados da NPM é o de que um modelo colegial baseado em docentes a desempenhar o papel de administradores é cada vez menos recorrente, privilegiando-se, cada vez mais, uma estrutura com administradores mais permanentes (Lorenz, 2007; Rhoades; Sporn, 2002). Em suma, estamos perante a "transição da colegialidade para a unipessoalidade" (Lima, 2009, p. 241).

Diante do exposto nos parágrafos anteriores, podemos concluir que as IES públicas foram forçadas a adaptar-se a esse novo cenário de elevados 
constrangimentos orçamentais que limitam sua atuação e administração, sem esquecer o abandono de suas formas tradicionais de administração perante a proliferação dos ideais da NPM.

Daqui decorre uma questão que necessita de resposta: Como podemos, em termos sintéticos, caraterizar as novas IES de cariz empresarial, imbuída dos preceitos e ideologias da NPM? Teichler (2003) responde a essa questão: diminuição dos controlos processuais por parte do poder central; aumento dos poderes de alocação dos recursos dentro das IES; aumento dos poderes de administração, ou seja, um crescente poder dos administradores dentro dessas organizações; um crescimento do número de profissionais no ensino superior combinado com uma redução do papel da profissão académica; e um papel cada vez importante de mecanismos de avaliação, accountability etc. Subsequentemente, o espírito empresarial e as noções relacionadas com corporate governance passaram a dominar o discurso atual (Clark, 2008; Marginson; Considine, 2000).

\section{AS ALTERAÇÕES NO FINANCIAMENTO DO ENSINO SUPERIOR PÚBLICO COMO DANOS COLATERAIS DA CRISE FINANCEIRA MUNDIAL E DO PARADIGMA DA NPM}

Em um contexto europeu, podemos recorrer ao relatório elaborado pela European University Association (EUA) intitulado Impact of the economic crisis on European universities (january 2011), reportando os efeitos da crise financeira nos sistemas de ensino superior europeus desde 2008. Embora o relatório já esteja um pouco datado e desatualizado, tal não invalida as ilações que dele podemos retirar. Assim, os resultados da monitorização contínua da crise realizada pelos Estados Unidos mostram claramente que os sistemas europeus de ensino superior foram afetados em diferentes estágios da crise e de forma muito diferente, o que reflete, em certa medida, o impacto que a crise teve sobre suas respetivas economias nacionais.

Dessa maneira, os fundos externos tornaram-se um recurso crítico para as IES públicas, atendendo a que essas organizações estão cada vez mais dependentes de um financiamento externo, em detrimento do financiamento público (cf. Decramer et al., 2012; Muscio; Qualione; Vallanti, 2013). Daí a diversificação do financiamento ser apontada como a solução final para as dificuldades financeiras das IES nos tempos que correm (Carter, 2012; Paradeise; Reale; Goastellec, 2009).

Adstrita a essa indispensabilidade da diversificação do financiamento das IES está igualmente a filosofia managerialista que está na base da NPM. Nessa ótica, a recente mercantilização do ensino superior também conduziu às conclusões reiteradas no parágrafo anterior: esse paradigma é sinónimo não só de uma maior concorrência pelo financiamento, mas também pela fragmentação da sua base, em que a fatia do financiamento estatal do sistema é reduzida e as fontes de financiamento são diversificadas (Boer; Goedegebuure, 2003), chegando mesmo o próprio Estado a incentivar as IES a reduzir sua dependência do financiamento público (Christensen, 2011; Horta, 2010; Paradeise; Reale; Goastellec, 2009). 
A lógica é a seguinte: considerando que, em essência, o modelo orientado para o mercado integra uma cultura empreendedora e de investimento em suas opções de financiamento (Estermann; Nokkala, 2009; Clark, 2008), uma solução apontada para fazer face a esses constrangimentos orçamentais será uma maior diversificação das fontes de financiamento das IES, podendo esta passar pela ligação dessas organizações públicas ao setor privado por meio, por exemplo, de investimentos estratégicos realizados diretamente pela própria instituição e que podem tomar a forma de, por exemplo, empresas start-up, spin-offs, transferência de conhecimento etc. (Sporn, 2006).

Outra forma de diversificação - e que corresponde a uma das mais importantes fontes de financiamento atuais - está em linha com os ideais doutrinários da NPM: o valor proveniente do pagamento de propinas e outras taxas de frequência de ciclos de estudos e outras ações de formação por parte de quem usufrui desse serviço (Scott, 2011; Willner; Grönblom, 2009). É o primado dos consumidores/ clientes, até porque, com o exponencial aumento dos contributos exigidos aos estudantes para o financiamento das IES, estes passaram a ver a si próprios como “clientes pagantes" (Scott, 2011, p. 230).

Dessa forma, podemos considerar que a tendência atual passa muito pelos condicionamentos financeiros impostos pelo poder central às IES (Scott, 2011; Willner; Grönblom, 2009), em virtude tanto dos constrangimentos orçamentais derivados da crise financeira como da introdução no ensino superior da NPM. Assim sendo, os fundos públicos destinados ao ensino superior público são cada vez mais escassos, com regras de controlo mais apertadas e assentes em contratos de financiamento baseado no desempenho (cf. Bogt; Scapens, 2012; Rocha, 2009), em que o orçamento fica vinculado a indicadores de desempenho mensuráveis, tais como diplomas, taxas de graduação, estatísticas de colocação de emprego ou pesquisa publicada (Vestrich, 2006) ou à assinatura de "um contrato entre a instituição e o Estado, contrato que estabelece quais as metas a atingir e qual a penalização, em termos de financiamento, em caso de incumprimento por parte da instituição" (Amaral, 2007, p. 27), ficando a transferência de fundos dependente da concretização dos objetivos a cumprir (Dobbins; Knill; Vögtle, 2011).

Nessa nova realidade, as IES decidem por si próprias como financiar suas operações e como serão gerados os resultados desejados (Jongbloed, 2003). Além disso, recai sobre a administração dessas organizações um maior poder de decisão sobre como os fundos são utilizados, podendo atribui-los, por exemplo, com base na produtividade dos departamentos. É, então, nesse contexto que os defensores dessa nova abordagem para a administração das IES defendem que "o comportamento empreendedor será cada vez mais a resposta para esse novo ambiente" e "para lidar com estes desafios complexos” (Sporn, 1999, p. 30). Conclusão: é ponto assente na atual literatura que trata o ensino superior, bem como de suas políticas e administração, que a introdução da retórica e das práticas de gestão do sector privado no ensino superior resultaram em mudanças consideráveis no funcionamento e financiamento das IES. 


\section{OS MODELOS HÍBRIDOS DE GOVERNAÇÃO DAS IES}

Podemos extrair dos dois pontos anteriores a influência que os constrangimentos orçamentais decorrentes da crise económica e financeira e a introdução da NPM exercem atualmente sobre a administração das IES. Todavia, tal não quer dizer que não existam vozes contra essa nova realidade. Por exemplo, no seio da literatura que especificamente trata do ensino superior, mas também na da ciência da administração pública, há muito que os princípios doutrinais da NPM são questionados e alvo de contundentes críticas. Sem nos alongarmos muito, podemos indicar que as especificidades das IES levaram a que algumas das técnicas de gestão emprestadas do setor privado não tenham sobrevivido às expectativas criadas. Por exemplo, Birnbaum (2000) alega que o fracasso da importação de várias técnicas de gestão para o ensino superior procedentes do setor privado pode dever-se à sua normativa, pois ignora as características tradicionais das IES, enquanto Kolsaker (2008, p. 516) refere que o efeito da NPM é, de alguma forma, negar as dimensões tradicionais do trabalho académico e tornar os académicos semelhantes a tarefeiros. Em suma, para as IES, a introdução dos princípios doutrinários da NPM significaram austeridade, a centralização e uma menor margem para a tomada de decisão democrática (Rhoades; Slaughter, 2004).

Além disso, a influência das tradições políticas e económicas dos diferentes países não são negligenciáveis, em termos do real impacto das doutrinas da NPM no ensino superior. Ou seja, não se pode subestimar as caraterísticas dos contextos locais, pois cada sistema nacional de ensino superior, incluindo sua administração, encontra-se impregnado de nuances que refletem as peculiaridades históricas e do próprio contexto económico-social de cada país (cf. Christensen, 2011; Clark, 1983; Dias, 2008; Dobbins; Knill; Vögtle, 2011; Lima; Azevedo; Catani, 2008; Paradeise; Reale; Goastellec, 2009).

Existe uma tendência de parte da literatura em assumir que as abordagens tradicionais de uma administração académica colegial estão a ser substituídas em todos os pontos do globo e em todos os níveis de administração das IES por processos de administração orientados por uma atitude empresarial, por uma visão mais individualista, a qual reforça o poder no topo; topo este que passou a ser dominado por um grupo de administradores especializados (Currie et al., 2003; Rhoades; Sporn, 2002; Teichler, 2003). A realidade, todavia, vem contradizer essa determinação teórica. Resumindo: é inequívoco que alguns países, como a Austrália (cf. Meek, 2003) e, em menor medida, a Holanda (cf. Boer, 2003), por exemplo, incorporaram substancialmente em seu ensino superior o que Trow (1994) denominou de hard academic managerialism, enquanto em outros esse estilo de administração do ensino superior largamente voltado para as regras do mercado já é considerado como tradicional, como é o caso dos Estados Unidos da América (cf. Maassen, 2008).

Todavia, a generalização dessa realidade não é lícita: por um lado, a colegialidade continua a apresentar, para alguns, múltiplas potencialidades, particularmente enquanto facilitador dos processos de inovação e mudança (Fullan, 1999), instrumento de desenvolvimento organizacional dos estabelecimentos de ensino (Harris; Bennett; Preedy, 1994) e fator de desenvolvimento pessoal e profissional dos 
docentes (Schön, 1983); por outro, embora a existência de pressão sobre IES para uma mudança seja irrefutável, na realidade as IES não abandonaram completamente o modelo colegial, o qual persiste, inclusive, em organizações onde foram realizadas reformas estruturais profundas, o que sugere um quadro muito mais complexo e diversificado (Santiago et al., 2006).

Currie et al. (2003, p. 187) concluíram que o "managerialismo como ideologia ainda não teve um grande impacto sobre as universidades europeias, talvez devido aos novos conceitos que estão a ser implementados por indivíduos que estão habituados às velhas regras e costumes". Considerando que cada país europeu segue sua própria agenda quanto à reforma desse sector (Maassen, 2008), essa observação será ainda mais correta para o Sul da Europa - e em alguns outros países do velho continente -, em que o afastamento da orientação colegial, em cujos órgãos estão representados docentes, discentes e pessoal não docente, tem sido muito lento, não refletindo essa perceção de um hard academic managerialism em um nível global (Santiago et al., 2006).

Shattock (2002, p. 243) defende, no entanto, o estabelecimento de um equilíbrio entre o modelo empresarial e o modelo consensual (colegial) de administração das IES: essas "funcionam melhor quando a sua administração é vista como uma parceria entre as abordagens empresarial e a colegial e onde um senso de desígnio comum documenta o balanço da relação". Essa nova perspetiva já passou para plano prático, como constata Horta (2010) em um contexto europeu. Nessa ótica, e segundo Maassen (2008, p. 85), podem ser observado em diversos países europeus modelos híbridos de governação das IES, “onde velhas e novas formas de princípios e práticas se misturam".

Essa mistura ou balanceamento entre a cultura tradicional e os imperativos de uma administração moderna introduz nesse debate o conceito das IES híbridas (cf. Christensen, 2011; Mouwen, 2000; Santiago, et al., 2006). De acordo com Mouwen (2000), uma IES híbrida não é mais que uma IES pública cuja parte substancial do financiamento deriva da mercantilização do ensino e da pesquisa, mesclando, dessa forma, e com sucesso, os objetivos tradicionais desse tipo de organização com uma mais moderna abordagem de cariz empresarial. A viabilidade desse tipo de instituições varia conforme o autor citado: enquanto para Mouwen (2000) esse será o modelo dominante de IES para o presente século, outros, como Currie et al. (2003), estão muito mais renitentes quanto às possibilidades de sucesso de um balanceamento eficaz entre essas duas perspetivas.

Em suma, embora se reconheça que as IES sejam organizações historicamente colegiais, também temos de aceitar, como fizeram Gibbons et al. (2004), que o sistema colegial tem de suportar a responsabilidade institucional e a accountability ou até mesmo ser mais empresarial, a fim de enfrentar os desafios do presente e do futuro. Por outras palavras, parece que a solução para as contínuas solicitações sobre as IES passa pela necessidade - deveras essencial - de estas abraçarem uma maior capacidade ao nível da administração (Machado; Taylor, 2010), permitindo uma administração mais flexível e eficaz (Amaral; Magalhães; Santiago, 2003). 


\section{O CASO PORTUGUÊS}

Muito do que foi descrito nas seções precedentes pode ser verificado no caso concreto das IES públicas portuguesas, visto que Portugal não ficou imune a essa aproximação às regras do mercado e ao paradigma da NPM (cf. Graça, 2009), e muito menos à atual crise financeira.

Foram vários os fatores internos que levaram ao aumento da pressão das doutrinas da NPM, não divergindo muito do que anteriormente foi referido neste trabalho: dificuldades relacionadas com o funcionamento do modelo tradicional burocrático-colegial em um sistema massificado (Amaral; Magalhães; Santiago, 2003); o declínio no número de candidatos de ensino superior como resultado de uma diminuição constante das taxas de natalidade; por conseguinte, o número de vagas no total, tanto nos setores público como no privado, ultrapassa largamente $o$ número de candidatos, o que faz com que as IES sejam forçadas a competir entre si em busca de mais clientes (alunos), o que, por sua vez, levanta a questão da necessidade de uma administração mais eficiente; pressões resultantes das dificuldades económicas e financeiras do país; e as novas políticas neoliberais iniciadas pelos governos socialistas, em meados da década de 1990, prosseguidas e reforçadas por governos posteriores (Santiago; Santos; Costa,2006). Aditam esses autores que essa retórica refletiu-se em diversa legislação, como a lei n. 38/1994, de 21 de novembro, que trata da avaliação dos programas de estudo, que enfatizava os critérios ligados à economia e à empregabilidade dos diplomados e que promoveu a presença de representantes dos empregadores nas equipas de avaliação.

As alterações ao nível do financiamento do ensino superior público, atrás explanadas, também se registaram em Portugal. Assim, muito embora o funcionamento das IES públicas fosse (quase) totalmente assegurado pelo orçamento do Estado, em um passado recente o contributo estatal para o financiamento do ensino superior diminuiu drasticamente, ou seja, nos últimos anos, as IES públicas portuguesas têm sido contempladas, consecutivamente, com uma receita inferior à que receberam no ano anterior (Cabrito, 2004). Essa diminuição de financiamento não pode deixar de constituir um fator de preocupação, especialmente tendo em consideração que as necessárias reformas de fundo a realizar no ensino superior português, designadamente quanto "a uma reorganização pedagógica profunda, exigem um esforço e investimento inicial muito significativo" (Simão; Santos; Costa, 2005, p. 45).

Para além disso, os responsáveis políticos estão a deslocar o financiamento público para a figura do contrato (Pacheco,2003). Tal é percetível no enquadramento legislativo atualmente em vigor e resultante da lei n. 62/2007, de 10 de setembroRegime Jurídico das Instituições de Ensino Superior (RJIES), já que esta prossegue a política de diversificação da base de financiamento das IES públicas e a existência de contratos de financiamento com base no desempenho já presente em legislação precedente (cf. lei n. 37/2003, de 22 de agosto), o que pode ser verificado ao longo de todo esse novo regime jurídico, embora, a nosso ver, esteja perfeitamente explícito em dois artigos. 
O primeiro é seu artigo $8^{\circ}$, que identifica as atribuições das IES, no âmbito da vocação própria de cada subsistema, particularmente quando atribui a estas a realização de ciclos de estudos visando a atribuição de graus académicos, bem como de outros cursos pós-secundários, de cursos de formação pós-graduada e outros; a transferência e valorização económica do conhecimento científico e tecnológico; a prestação de serviços à comunidade e de apoio ao desenvolvimento; a produção e difusão do conhecimento e da cultura; a realização de investigação e o apoio e participação em instituições científicas; a realização de ações de formação profissional e de atualização de conhecimentos; a cooperação e o intercâmbio cultural, científico e técnico com instituições congéneres, nacionais e estrangeiras, entre outras.

O segundo é o artigo 115, visto que este indica explicitamente que são receitas dessas organizações as dotações orçamentais que lhes forem atribuídas pelo Estado; as receitas provenientes do pagamento de propinas e outras taxas de frequência de ciclos de estudos e outras ações de formação; as receitas provenientes de contratos de financiamento plurianual celebrados com o Estado; as receitas provenientes de atividades de investigação e desenvolvimento; os rendimentos da propriedade intelectual; os rendimentos de bens próprios ou de que tenham a fruição; as receitas derivadas da prestação de serviços, emissão de pareceres e da venda de publicações e de outros produtos da sua atividade; os subsídios, as subvenções, as comparticipações, as doações, as heranças e os legados; o produto da venda ou arrendamento de bens imóveis; os juros de contas de depósitos e a remuneração de outras aplicações financeiras; os saldos da conta de gerência de anos anteriores; o produto de taxas, emolumentos, multas, coimas e quaisquer outras receitas que legalmente lhes advenham; o produto de empréstimos contraídos; entres outras receitas previstas em termos legais.

Desse elenco de receitas, é de assinalar o caso das propinas e outras taxas de frequência de ciclos de estudos e outras ações de formação, ou seja, a cobrança direta aos clientes pelo serviço prestado. Em Portugal, o peso dessas receitas aumentou dramaticamente desde a revolução de abril de 1974. Assim, de um preço simbólico nos anos imediatamente a seguir à Revolução de 1974 (cerca de 6 euros por ano, entre 1974 e 1986), a taxa de frequência foi crescendo até chegar ao valor dos dias de hoje (por exemplo, o valor máximo a cobrar nas licenciaturas, no ano letivo 2012/2013, é de 1.037,20 euros).

Mesmo na presença de alguns limites quanto ao valor a cobrar - no caso das licenciaturas e dos mestrados integrados -, não podemos deixar de referir a (relativa) liberdade dadas às IES portuguesas na fixação do valor a cobrar pelo serviço prestado (cf. lei n. 37/2003, de 22 de agosto), o que permite inferir explicitamente sobre a presença das mais fundamentais regras do mercado no que à livre concorrência e à oferta e procura diz respeito. Mesmo os próprios argumentos usados como justificação apresentados por diversos governos para a existência desse tipo de financiamento, compilados por Cabrito (2004), são decalcados das doutrinas da NPM: uma vez que o maior beneficiário do ensino superior é o aluno, então este deverá pagar pelo serviço obtido, em uma lógica de utilizador-pagador; tornando-se um financiador das instituições, o estudante tem maior controlo sobre o sistema, podendo exigir um ensino de melhor qualidade; etc. 
Retomando a peça legislativa de importância capital que é o RJIES, Lima (2009) garante que este ganha outra inteligibilidade à luz das máximas político-gestionárias anteriormente referidas. De momento, e procurando evitar um aprofundamento desnecessário e inútil desse diploma legal, tendo em conta os objetivos deste trabalho, podemos recorrer ao trabalho de Ferreira (2009) para realçar os principais aspetos introduzidos pela citada lei e que muito dizem ao primado da NPM. Dessa forma, essa legislação introduziu diversas inovações, incluindo uma maior diversificação do sistema de administração das IES, tendo estabelecido os princípios de organização do sistema de ensino superior, definindo a autonomia das IES, incluindo a livre administração de seus recursos humanos (tendo em consideração suas necessidades e os princípios de boa administração e no estrito respeito de suas disponibilidades orçamentais), bem como sua accountability e estabelecendo órgãos de gestão com participação externa.

Em contrapartida, permite maior diversidade de organização e de estatuto legal das IES públicas, com a novidade de essas poderem tornar-se fundações públicas de direito privado, para além de permitir a constituição de consórcios. O financiamento público das IES também não ficou esquecido e deverá evoluir para um sistema de contratos institucionais, ligado aos objetivos nacionais, com base em planos estratégicos e indicadores de desempenho. Esse regime propõe, em particular, uma maior diversificação, que deverá repercutir na forma de financiamento individualizado, o qual deverá substituir gradualmente o mecanismo atual de distribuição do financiamento público, nomeadamente por meio de uma efetiva abertura dos órgãos de governo dessas instituições à comunidade onde estão inseridas.

Aqui também não pode deixar de ser referido que, embora a capacidade de elaboração de estatutos próprios por parte de cada instituição, na observância do RJIES, represente uma prerrogativa de grande importância em termos de receção e de latitude de soluções organizacionais e de governo, o sistema de governo e a macroestrutura organizacional adotados tendem, na opinião de Lima (2009), para uma subvalorização das práticas democráticas e participativas no interior das escolas, faculdades, departamentos e outras subunidades orgânicas, o que estará patente na regulamentação dos órgãos de governo - regulados com detalhe nesse diploma legal - das IES: conselho geral; reitor ou presidente; e conselho de gestão.

O conselho geral é o órgão máximo de governo, embora de dimensão mínima em termos de participação e representação democráticas, apenas composto por 15 a 35 membros - variando de acordo com os estatutos da respetiva IES (por exemplo, de acordo com Oliveira [2012], a Universidade do Porto, a de Lisboa e a do Minho têm 23 membros, enquanto a de Coimbra e a do Algarve têm 35 ) -, integrando docentes e investigadores doutorados (necessariamente mais de metade dos membros); compreendendo, pelo menos, $15 \%$ de representantes do corpo discente; eventualmente (mas não necessariamente), funcionários não docentes; e ainda, obrigatoriamente, pelo menos $30 \%$ de membros externos de reconhecido mérito cooptados pelos membros eleitos deste órgão, cabendo a um destes presidi-lo (cf. artigos 81 e 82 ). 
Esse conselho é eleito pela academia, cabendo aos docentes e investigadores eleger por voto universal e método proporcional seus representantes, o mesmo sucedendo com os estudantes e, se for caso disso, com o pessoal não docente, cabendo a este eleger o reitor ou presidente, aprovar alterações aos estatutos, apreciar os atos de administração do reitor e do conselho de gestão, aprovar o plano anual de atividades e o orçamento, fixar as propinas devidas pelos estudantes, apreciar o relatório de atividades e aprovar as contas, criar ou extinguir unidades orgânicas, aprovar o plano estratégico de médio prazo da respetiva IES e as linhas gerais desta; e propor iniciativas para o bom funcionamento da instituição. No entanto, não interfere no governo e na administração quotidianos o que compete ao reitor ou ao presidente.

Os reitores e os presidentes serão os verdadeiros líderes das instituições, concentrando em si um numeroso conjunto de competências, designadamente os poderes próprios relacionados com a administração da IES, incluindo a abertura de concursos de pessoal docente e não docente (cf. artigo 92), sendo coadjuvados por vice-reitores ou vice-presidentes por estes livremente nomeados. A estes deve ser acrescentado a figura do administrador, escolhido entre pessoas com saber e experiência na área da administração, com competência para a gestão corrente da instituição e a coordenação de seus serviços, sob direção do reitor ou presidente, a quem cabe sua nomeação e exoneração.

Segundo refere Lima (2009), parte das competências atualmente pertencentes ao reitor ou ao presidente era anteriormente atribuída ao senado, o que será uma mais-valia do novo sistema diante do anterior assente em um senado com excessivo número de membros. Nesse momento, porém, o senado é de criação facultativa e de natureza consultiva, desaparecendo ainda a anterior assembleia. Conclui-se, dessa forma, que a liderança individual ganha grande centralidade em termos de governo, até mesmo no caso da maioria das competências exercidas pelo conselho geral, ao qual cabe a aprovação dos mais importantes planos e documentos estratégicos das instituições, sempre sob proposta do reitor ou presidente, órgão a quem compete a "condução da política da instituição" (artigo 85, n. 2).

Para além do conselho geral (órgão deliberativo) e da figura do reitor ou presidente (órgão executivo), ainda temos de referir o órgão que completa o triunvirato do governo das IES: o conselho de gestão. Este é designado e presidido pelo reitor ou presidente, conforme os casos, sendo composto por um máximo de cinco membros, nos termos previstos nos estatutos da instituição, incluindo um vice-reitor ou vice-presidente e o administrador. Todavia, podem ser convocados para participar em suas reuniões, mas sem direito a voto, os diretores ou presidentes das unidades orgânicas, os responsáveis pelos serviços da instituição e representantes dos estudantes e do pessoal não docente e não investigador. Quanto às competências desse órgão, estas passam pela condução da gestão administrativa, patrimonial e financeira da instituição, bem como a administração dos recursos humanos dentro das limitações impostas pela forte tradição legalista do sector público português, que pode ser visto, por exemplo, pelo sistema de carreiras vigente, para além de fixar as taxas e emolumentos. 
Paralelamente, a autonomia total das IES públicas portuguesas diante do poder central ainda continua a ser uma perfeita utopia. Os artigos 26 e 27 do RJIES, nos quais estão definidas as atribuições do Estado e as competências do governo em matéria do ensino superior, evidenciam isso mesmo. Entre essas podemos destacar, por exemplo, a incumbência do Estado de financiar as IES públicas e de apoiar os investimentos e iniciativas que promovam a melhoria da qualidade do ensino; ou o facto de competir ao governo criar, modificar, fundir, cindir e extinguir IES públicas, enquanto compete em especial ao ministro da tutela intervir no processo de fixação do número máximo de novas admissões e de inscrições.

\section{CONCLUSÕES, LIMITAÇÕES E PISTAS PARA TRABALHOS FUTUROS}

$\mathrm{O}$ atual ambiente em que as IES públicas inserem-se foi primordial para as alterações que se fizeram sentir no nível de sua administração. De importância capital para as mudanças a que se assistiram, a introdução das doutrinas da NPM nas IES provocou, entre outros aspetos, a competição por alunos e por financiamento para a investigação; o pagamento de valores cada vez mais avultados por parte de quem usufrui desse serviço público; o financiamento com base em resultados, sobressaindo a figura do contrato de desempenho que estabelece quais as metas a atingir e qual a penalização, em termos de financiamento, em caso de incumprimento; a avaliação institucional; a deriva para um espírito empresarial; e a cooperação com o setor privado, por meio de empresas start-up, spin-offs, transferência de conhecimento etc.

$\mathrm{O}$ desembaraço com que esses ideais introduziram-se e disseminaram-se muito se deve ao facto de as formas tradicionais de administração académica baseadas na colegialidade serem vistas (por muitos) como obsoletas, ineficazes e ineficientes. Como tal, assistiu-se a uma alteração do papel dos docentes no desempenho das funções dirigentes, designadamente quanto à sua remoção - e dos órgãos colegiais - do centro da tomada de decisão, em detrimento de uma maior profissionalização da administração, ou seja, assistiu-se a um crescente interesse por uma administração mais profissionalizada, obtida por meio do recurso a profissionais especializados em administração, o que vai de encontro às componentes doutrinais da NPM. Por outras palavras, estamos perante um gradual processo de transferência entre a colegialidade e a unipessoalidade.

Aliadas à emergência da NPM, as políticas de austeridade e de restrição a nível orçamental, decorrentes da atual crise económica e financeira global, levaram a alterações de monta no ensino superior público: subfinanciamento estatal, o que levou à necessidade de diversificação do financiamento, nomeadamente o obtido mediante a investigação aplicada, da prestação de serviços de consultoria à comunidade ou na procura de mecenato; incremento do fenómeno das fusões; downsizing; redução dos salários; aumento da competição pelo financiamento, o que traz a ameaça de uma fragmentação excessiva das fontes de financiamento; perda de qualidade do ensino superior; declínio da proporção do pessoal efetivo, por meio da tendência para o aumento da precariedade do emprego e do recurso a contratos de trabalho a tempo parcial, ou seja, a contratualização a tempo parcial e de curto 
prazo tornou-se uma política de administração de recursos humanos cada vez mais usual nas IES; entre outros aspetos.

Todavia, a generalização dessa realidade para todos os países não é lícita. As alterações prosseguidas divergem de país para país, fruto das particularidades de seu contexto político, económico, social, cultural e histórico, além de que o paradigma da NPM tampouco teve uma aceitação universal, deparando-se com severas e contundentes críticas. Não obstante ser irrefutável a existência de pressão sobre IES para uma mudança, a realidade demonstra que essas instituições nunca chegaram a abandonar por completo o modelo colegial, o qual prevaleceu mesmo em organizações alvo de reformas estruturais profundas. Dito de outra forma, a prática provou que foram raros os casos em que as IES adotaram na íntegra a perspetiva de hard academic managerialism em sua administração. A resposta passou por uma opção de balanceamento equilibrado entre o modelo empresarial e o modelo consensual (colegial), por meio de um modelo híbrido de governação das IES, que permite uma administração mais flexível e eficaz.

Muito do que antes foi descrito verificou-se no caso concreto da administração das IES públicas portuguesas, o que só prova que nosso país não ficou de fora nessa aproximação às regras do mercado e ao paradigma da NPM e não deixou de sofrer as maleitas da crise financeira e económica global. As razões não se afastam muito das verificadas em outros países que também introduziram, em maior ou menor grau, os ideais managerialistas: dificuldades relacionadas com o funcionamento do modelo tradicional burocrático-colegial em um sistema massificado; o declínio do número de candidatos ao ensino superior português como resultado de uma diminuição constante das taxas de natalidade e, por conseguinte, do número de vagas no total, o que faz com que as IES sejam forçadas a competirem entre si em busca de mais clientes (alunos), o que, por sua vez, levanta a questão da necessidade de uma administração mais eficiente; as pressões resultantes das dificuldades económicas e financeiras do país e que se agravaram a partir do estalar da crise económica e financeira em 2008; e as novas políticas neoliberais iniciadas pelos governos socialistas, em meados da década de 1990, prosseguidas e reforçadas por governos posteriores.

As mudanças registadas em Portugal são várias e de diversa ordem, muitas delas decorrentes do RJIES, a saber: uma política de diversificação da base de financiamento das IES públicas; a existência de contratos de financiamento com base no desempenho; o decréscimo do financiamento público ao mesmo tempo que cresce o valor arrecadado por meio de receitas próprias, de onde se destacam as propinas e outras taxas de frequência, ou seja, o aumento da cobrança aos clientes pelo serviço prestado (educação superior); presença das mais básicas regras do mercado ao ser concedida às IES públicas a prerrogativa de uma (relativa) liberdade na fixação do valor a cobrar pelos serviços prestados, o que permitirá a essas instituições competir por alunos por meio do preço.

Acrescente-se ainda que, não obstante o triunvirato de governo estabelecido por novo regime jurídico (conselho geral, o conselho de gestão e reitor ou presidente) conter órgãos de cariz colegial, não pode deixar de ser salientada a particularidade de essa peça jurídica evidenciar uma clara preferência por uma liderança individual, 
na figura do reitor ou presidente (vide as funções e poderes desse órgão de governo, de cariz executivo), em detrimento da colegialidade, que perde importância nesse novo modelo de governação das IES (vide a supressão da anterior assembleia ou o facto de o senado agora ser de criação facultativa e de natureza consultiva), bem como a pertinência de alguns dos lugares desses órgãos colegiais terem de ser ocupados por figuras externas à academia, diminuindo a presença no centro de poder tanto de funcionários não docentes como dos próprios docentes, muito em linha com as doutrinas da NPM.

Em suma, em Portugal ainda não estaremos perto de um hard academic managerialism, em grande parte por culpa da forte cultura conservadora das instituições públicas portuguesas e da forte tradição legalista do sector público português fruto da tradição administrativa napoleónica presente no território português, o que, aliás, é uma caraterística transversal a toda a sociedade portuguesa. Ao contrário, aproxima-se de um modelo híbrido nos moldes suprarreferenciados.

Em termos de limitações do trabalho, reconhece-se que a vertiginosa sucessão de acontecimentos pautados pela incerteza dos dias que correm levará a uma desatualização do que aqui foi dito.

Todavia, um dos caminhos a seguir no futuro poderá ser o da elaboração de estudos comparativos em nível internacional, principalmente com outros países europeus que se debatem atualmente com as mesmas dificuldades económicas e financeiras (i.e. Grécia, Espanha, Irlanda ou Itália), o que permitiria comparar as políticas prosseguidas quanto à administração de suas IES públicas e se estas se enquadram, ou não, no paradigma da NPM. Em termos nacionais, uma hipótese de trabalho poderia ser a elaboração de um estudo da precarização dos funcionários das IES, em particular de seus corpos docentes.

\section{REFERÊNCIAS}

Amaral, A. A reforma do ensino superior português. In: Conselho Nacional de Educação (Org.). Políticas de ensino superior: quatro temas em debate - Seminário Políticas de ensino superior. Lisboa: Conselho Nacional de Educação, 2007. p. 17-37. ; Magalhães, A.; Santiago, R. The rise of academic managerialism in Portugal. In: __ Meek, V. L.; Larsen, I. M. (Orgs.). The higher education managerial revolution? Dortrecht: Kluwer Academic Publishers, 2003. p. 131-153. Andrews, R.; Boyne, G. A.; Walker, R. M. Overspending in public organizations: does strategic management matter? International Public Management Journal, London: Routledge, v. 15, n. 1, p. 39-61, 2012.

Birnbaum, R. Management fads in higher education, where they come from, what they do, why they fail. San Francisco: Jossey-Bass, 2000.

Boer, H. Who's afraid of red, yellow and blue? The colourful world of management reforms. In: Amaral, A.; Meek, V. L.; Larsen, I. M. (Orgs.). The higher education managerial revolution? Dortrecht: Kluwer Academic Publishers, 2003. p. 89-108. 
; Goedebebuure, L. New rules of the game? Reflections on governance, management, and systems change. In: File, J.; Goedegebuure, L. (Orgs.). Real-time systems: reflections on higher education in the Czech Republic, Hungary, Poland, and Slovenia. Enschede: CHEPS Centre for Higher Education Policy Studies, University of Twente, 2003. p. 207-234.

Bogt, H. J.; Scapens, R. W. Performance management in universities: effects of the transition to more quantitative measurement systems. European Accounting Review, Brussels: European Accounting Association, v. 21, n. 3, p. 451-497, 2012.

Boyer, R. The four fallacies of contemporary austerity policies: the lost keynesian legacy. Cambridge Journal of Economics, Cambridge: Oxford University Press, v. 36, n. 1, p. 283-312, 2012.

CAbrito, B. G. O financiamento do ensino superior em Portugal: entre o Estado e o mercado. Educação e Sociedade, Campinas: CEDES, v. 25, n. 88, p. 977-996, 2004.

Carter, J. C. Quality cutting: perceived faculty and staff effects of State budget cuts on institutional quality. Public Organization Review, Amsterdam: Springer, v. 12, n. 1, p. 41-56, 2012.

Christensen, T. University governance reforms: potential problems of more autonomy? Higher Education, Amsterdam: Springer, v. 62, n. 4, p. 503-517, 2011.

CLARK, B. R. The higher education system: academic organization in cross-national perspective. Berkeley: University of California Press, 1983.

. Creating entrepreneurial universities: organisational pathways of transformation. 2. ed. New York: Pergamon Press, 2008.

Currie, J.; Deangelis, R.; Boer, H.; Huisman, J.; Lacotte, C. Globalizing practices and university responses: european and anglo-american differences. Westport: Greenwood Publishing Group, 2003.

Decramer, A.; Smolders, C.; Vawderstraeten, A.; Christiaens, J.; Desmidt,S. External pressures affecting the adoption of employee performance management in higher education institutions. Personnel Review, Bingley: Emerald, v. 41, n. 6, p. 686$-704,2012$.

DeShields, O.W.; Kara, A.; Kaynak, E. Determinants of business student satisfaction and retention in higher education: applying Herzberg's two-factor theory. International Journal of Educational Management, Bingley: Emerald, v. 19, n. 2, p. 128-139, 2005.

Dias, M.C. Participação e poder na escola (1986-2004). Lisboa: Edições Colibri; Instituto Politécnico de Lisboa, 2008.

Dobbins, M.; Knill, C.; Vögtle, E. M. An analytical framework for the cross-country comparison of higher education governance. Higher Education, Amsterdam: Springer, v. 62, n. 5, p. 665-683, 2011.

Estermann, T.; Nokkala, T. University autonomy in Europe: exploratory study. Brussels: European University Association, 2009.

European University Association - EUA. Impact of the economic crisis on European universities (january 2011). 2011. Disponível em: <http://www.eua.be/News/11-0107/ 
Impact_of_the_economic_crisis_on_European_higher_education_EUA_publishes_ latest_update_ahead_of_major_new_report.aspx>. Acesso em: 6 jun. 2012.

Ferlie, E.; Ashburner, L.; Fitzgerald, L.; Pettigrew, A. The New Public Management in action. Oxford: Oxford University Press, 1996.

; Musselin, C.; Andresani, G. The steering of higher education systems: a public management perspective. Higher Education, Amsterdam: Springer, v. 56, n. 3, p. 325-348, 2008.

Ferreira, M. Ensino superior: o desafio europeu. Notandum-Libro, São Paulo: CEMOrOce e IJI; Porto: Universidade do Porto, n. 13, p. 15-20, 2009.

Fullan, M. Change forces: the sequel. London: Falmer Press, 1999.

Gibbons, M.; Limoges, C.; Nowotny, H.; Schwartzman, S.; Scott, P.; Trow, M. The new production of knowledge: the dynamics of science and research. London: Sage, 2004. Graça, V. Sobre o financiamento da educação: condicionantes globais e realidades nacionais. Revista Lusófona de Educação, Lisboa: Centro de Estudos Interdisciplinares em Educação e Desenvolvimento, n. 13, p. 49-80, 2009.

Harris, A.; Bennett, N.; Preedy, M. Organizational effectiveness and improvement in education. Buckingham: Open University Press, 1994.

Hoon, C. A public management for all seasons? Public Administration, Oxford: Wiley-Blackwell, v. 69, n. 1, p. 3-19, 1991.

Horta, H. The role of the state in the internationalization of universities in catching-up countries: an analysis of the portuguese higher education system. Higher Education Policy, Paris: International Association of Universities, n. 23, p. 63-81, 2010.

Humes, W. The discourses of educational management. Journal of Educational Enquiry, Adelaide: Centre for Research in Education (CREd), v. 1, n. 1, p. 35-53, 2000.

Johnstone, B.; Teferra, D. Introduction. Journal of Higher Education in Africa, Dakar: Council for the Development of Social Science Research in Africa, v. 2, n. 2, p. 1-5, 2004. Kaboolian, L. The New Public Management: challenging the boundaries of the management vs. Administration debate. Public Administration Review, Oxford: Wiley-Blackwell, v. 58, n. 3, p. 189-193, 1998.

Kettr, D. F. The global revolution in public management: driving themes, missing links. Journal of Policy Analysis and Management, Hoboken: John Wiley \& Sons, v. 16, n. 3, p. 446-462, 1997.

Kolsaker, A. Academic professionalism in the managerialist era: a study of english universities. Studies in Higher Education, London: Routledge, v. 33, n. 5, p. 513-525, 2008. Lains, P. A crise em 2012. Relações Internacionais, Lisboa: Instituto Português de Relações Internacionais, n. 33, p. 43-52, 2012.

LAne, J.-E. The public sector: concepts, models and approaches. 3. ed. London: Sage Publications, 2000.

Lima, L. C. A democratização do governo das escolas públicas em Portugal. Sociologia, Porto: Editora Universidade do Porto, n. 19, p. 227-253, 2009. 
; Azevedo, M. L. N.; Catani, A. M. O processo de Bolonha, a avaliação da educação superior e algumas considerações sobre a universidade nova. Avaliação da Educação Superior, Campinas: Rede de Avaliação Institucional da Educação Superior, v. 13, n. 1, p. 7-36, 2008.

Lodge, M.; Hood, C. Into an age of multiple austerities? Public management and public service bargains across OECD countries. Governance: an International Journal of Policy, Administration, and Institutions, Hoboken: Wiley Periodicals, v. 25, n. 1, p. 79-101, 2012. Lorenz, C. L'économie de la connaissance, le nouveau management public et les politiques de l'enseignement supérieur dans l'Union Européenne. In: Charle, C.; Soulie, C. (Orgs.). Les ravages de la "modernisation" universitaire en Europe. Paris: Éditions Syllepse. p. 33-52, 2007.

MaAssen, P. The modernization of higher education governance in Europe. In: Amaral, A. (Org.). Politicas de ensino superior: quatro temas em debate. Lisboa: Conselho Nacional de Educação, 2008. p. 71-106.

Machado, M. L.; TaYloR, J. S. The struggle for strategic planning in european higher education: the case of Portugal. Research in Higher Education Journal, Amsterdam: Springer, n. 6, p. 1-20, 2010.

Marginson, S.; Considine, M. The enterprise university: power, governance and reinvention in Australian. Cambridge: Cambridge University Press, 2000.

McCann, L. Reforming public services after the crash: the roles of framing and hoping. Public Administration, Oxford: Wiley-Blackwell, v. 91, n. 1, p. 5-16, 2013.

Меeк, V. L. Governance and management of Australian higher education: enemies within and without. In: Amaral, A.; Meek, V. L.; Larsen, I. M. (Orgs.). The higher education managerial revolution? Dortrecht: Kluwer Academic Publishers, 2003. p. $179-201$.

Mouwen, K. Strategy, structure and culture of the hybird university: towards the university of the 21st century. Tertiary Education and Management, Amsterdam: European Association for Institutional Research, v. 6, n. 1, p. 47-56, 2000.

Muscio; A.; Quaglione, D.; Vallanti, G. Does government funding complement or substitute private research funding to universities? Research Policy, Melbourne: Elsevier, n. 42, p. 63-75, 2013.

Oliveira, A. C. O risco da irrelevância dos conselhos gerais das universidades. Ensino Superior, Lisboa: Sindicato Nacional do Ensino Superior, n. 43, p. 18-19, 2012.

Pacheco, J. A. Políticas educativas para o ensino superior na União Europeia: um olhar do lado português. Educação E Sociedade, Campinas: CEDES, v. 24, n. 82, p. 17-36, 2003.

Paradeise, C.; Reale, E.; Goastellec, G. A comparative approach to Higher Education Reforms in Western European countries. In: PARAdeise, C. et al. (Orgs.). University governance: Western European perspectives, higher education dynamics. Dordrecht: Springer, 2009. v. 25, p. 197-225.

Pollitt, C.; Bouckaert, G. Public management reform: a comparative analysis. 2. ed. Oxford: Oxford University Press, 2004. 
Rhoades, G.; Slaughter, S. Academic capitalism in the new economy: challenges and choices. American Academic, Los Angeles: Center for the Study of Higher Education, v. 1, n. 1, p. 37-59, 2004.

; Sporn, B. New models of management and shifting modes and costs of production: Europe and the United States. Tertiary Education and Management, Amsterdam: European Association for Institutional Research, v. 8, n. 1, p. 3-28, 2002.

Rocha, J.A. O. Modelos de gestão pública. Revista de Administração e Políticas Públicas, Braga, Núcleo de Estudos em Administração e Políticas Públicas, v. I, n. 1, p. 6-16, 2000. . Gestão pública e modernização administrativa. Lisboa: INA, 2009.

Rosa, M. J.; Saraiva, P. M.; Diz, H. Defining strategic and excellence bases for the development of portuguese higher education. European Journal of Education, Hoboken: Wiley Periodicals, v. 40, n. 2, p. 205-221, 2005.

Santiago, R. O conceito de qualidade no ensino superior. In: Instituto Nacional de Administração (Org.). A avaliação na administração pública. Acta Geral do 1o Encontro INA. Lisboa: Instituto Nacional de Administração, 1998. p. 355-379.

Santiago, R.; Carvalho, T.; Amaral, A.; Meek, V. L. Changing patterns in the middle management of higher education institutions: the case of Portugal. Higher Education, Amsterdam: Springer, v. 52, n. 2, p. 215-250, 2006.

Schön, D. A. The reflective practitioner: how professionals think in action. New York: Basic Books, 1983.

Scotт, P. Leadership in universities. The International Journal of Leadership in Public Services, Bingley: Emerald, v. 7, n. 3, p. 229-234, 2011.

Sнаттоск, M. Re-balancing Modern Concepts of University Governance. Higher Education Quarterly, Hoboken: Wiley Periodicals, v. 56, n. 3, p. 235-244, 2002.

Simão,J. V.; Santos, S. M.; Costa, A. A. Ambição para a excelência: a oportunidade de Bolonha. Lisboa: Gradiva, 2005.

Sporn, B. Adaptive university structures: an analysis of adaptation to socioeconomic environments of US and european universities. London: Jessica Kingsley Publishers, 1999.

Governance and administration. In: Forest, J. J. F.; Аlтbach, P. G. (Orgs.). International handbook of higher education, part one. Dordrecht: Springer, 2006. p. 141-157.

TANG, T. L.-P.; TANG, T. L.-N. The love of money, pay satisfaction and academic tenure: professors in a public institution of higher education. Public Personnel Management, Thousand Oaks: Sage Publications, v. 41, n. 1, p. 97-126, 2012.

TeIchler, U. The future of higher education and the future of higher education research. Tertiary Education and Management, Amsterdam: European Association for Institutional Research, v. 9, n. 3, p. 171-185, 2003.

Trow, M. Managerialism and the academic profession: the case of England. Higher Educational Policy, Paris: International Association of Universities, v. 7, n. 2, p. 11-18, 1994. 
Vestrich, R.M.The academy under siege: threats to teaching and learning in american higher education. American Academic, Los Angeles: Center for the Study of Higher Education, v. 2, n. 1, p. 55-71, 2006.

Willner, J.; Grönblom, S. The impact of budget cuts and incentive wages on academic work. International Review of Applied Economics, v. 23, n. 6, p. 673-689, 2009.

Zagelmeyer, S.; Gollan, P. J. Exploring terra incognita: preliminary reflections on the impact of the global financial crisis upon human resource management. The International Journal of Human Resource Management, Oxfordshire: Routledge, v. 23, n. 16, p. 3.287-3.294, 2012.

ZaHARIA, S. A comparative overview of some fundamental aspects of university management as practiced in several european countries. Higher Education in Europe, Oxfordshire: Routledge, v. 27, n. 3, p. 301-311, 2002.

\section{SOBRE OS AUTORES}

Miguel Lira é doutor em gestão pela Universidade Aberta (Portugal). Professor assistente do Instituto Politécnico de Coimbra (Portugal). E-mail:mlira@iscac.pt

Miguel Gonçalves é mestre em contabilidade e auditoria pela Universidade de Aveiro (Portugal). Professor assistente do Instituto Politécnico de Coimbra (Portugal). E-mail: mgoncalves@iscac.pt

Maria da Conceição da Costa Marques é doutora em gestão pela Universidade Aberta (Portugal). Professora do Instituto Politécnico de Coimbra (Portugal).

E-mail:mmarques@iscac.pt 